\title{
Pancreatic Fistula
}

National Cancer Institute

\section{Source}

National Cancer Institute. Pancreatic Fistula. NCI Thesaurus. Code C79701.

An abnormal communication between the pancreas and another org an or cavity. 